\title{
Developing a Methodology for Determining Design and operating Requirements for Contracting Tunnel Works
}

\author{
Nikolaos Vagiokas \\ Enalos PC, Athens, Greece \\ Email: vagiokas@gmail.com
}

How to cite this paper: Vagiokas, N. (2018) Developing a Methodology for Determining Design and Operating Requirements for Contracting Tunnel Works. Open Access Library Journal, 5: e4741.

https://doi.org/10.4236/oalib.1104741

Received: June 26, 2018

Accepted: July 10, 2018

Published: July 13, 2018

Copyright $\odot 2018$ by authors and Open Access Library Inc.

This work is licensed under the Creative Commons Attribution International License (CC BY 4.0).

http://creativecommons.org/licenses/by/4.0/

\begin{abstract}
Directive 2004/54/EC [1] on minimum safety requirements for tunnels in the trans-European road network sets the bases for establishing an acceptable safety level for tunnel users across EU member states. Furthermore, many EU member states enforce stricter safety requirements for tunnels in their territory. The lack of a methodology for determining design and operating requirements for tunnels leads many times to an expensive over-design for tunnel works and thereafter operation and maintenance, throughout the tunnel lifetime without the expected increase in safety levels. In the present paper a methodology has been developed in order to assist all parties involved in contracting tunnel works to establish the optimum design and operating requirements. The methodology combines results of risk analysis with cost benefit analysis in different time periods throughout the tunnel design life. The results from implementing the aforementioned methodology include the optimum set of design and operating requirements for each tunnel under consideration. Concluding, the necessary contribution of each beneficiary to the funding of the different sets of design and operating requirements for certain time periods throughout tunnel lifetime, is soundly estimated and justified. The proposed methodology is an excellent tool since it can be used regardless of specific risk acceptance criteria.
\end{abstract}

\section{Subject Areas}

Transport, Safety

\section{Keywords}

Tunnel Safety, Tunnel Operation, Tunnel Maintenance, Cost Benefit Analysis 


\section{Introduction}

In the trans-European road network, the minimum safety requirements for road tunnels are imposed by Directive 2004/54/EC [1]. By this it is established a uniform minimum safety level for road tunnel users throughout European Union. Furthermore, since different societies have different tolerance to risk depending on a number of parameters, member states have established additional requirements to enhance road tunnel safety levels in their road networks. These requirements involve both design and operating specifications that are applicable to all tunnels depending mainly on their length. Since there are no two identical tubes even of the same tunnel-having at least opposite slopes-each tunnel and furthermore each tube should be considered unique. Therefore, it is very important to determine the design and operating requirements for each tunnel in particular and not under general guidelines. The safety level and risk acceptance criteria should be uniform for all tunnels, but the safety level for each tunnel can be achieved only by a particular set of design and operating requirements including structural elements, equipment specifications and operational standards.

Minimum safety levels are established by the proper combination of tunnel design and operation procedures. Minimum safety levels refer mostly to road accidents that can result in numerous fatalities, mainly due to domino effects of the accident outcome involving a fire or release of hazardous material. Although road accident frequencies with one or two fatalities are disproportionally larger to road accident frequencies with multiple fatalities, societies are risk averse and do not tolerate multiple fatality accidents. The tunnel environment is a confined space where consequences of fire or hazardous material releases are more severe than in the open road. A road accident with a subsequent fire in the open road will have a damage potential limited to the vehicles involved, while in a tunnel environment the subsequent fire may produce enough smoke with a damage potential to the rest of the tunnel users not involved in the accident. The same undesirable consequences resulting from toxic material releases and explosions are more probable inside a tunnel than in the open road. Therefore, specific measures should be envisaged to reduce the frequency of such accidents and mitigate their consequences. Such measures involve emergency exits between tunnel tubes to provide shorter escape routes for tunnel users compared to escaping from the tunnel portals. The necessary distance between the emergency exits depends on the available time that tunnel users have before the smoke propagates over them causing suffocation. This time involves realization and reaction time along with the necessary time to reach the emergency exit, which determines the maximum allowable interval between emergency exits. Since realization and reaction time can be decreased by efficient accident detection and public-address systems, emergency exit intervals can be increased accordingly. Therefore, an optimum set of design and operation requirements can be established (Table 1).

The proposed methodology combines results of risk analysis with cost benefit 
Table 1. Safety measures for road tunnel design and operation.

\begin{tabular}{lll}
\hline & $\begin{array}{l}\text { Structural \& Electro-Mechanical } \\
\text { measures }\end{array}$ & Operational measures \\
\hline $\begin{array}{l}\text { Decreasing of } \\
\text { accident } \\
\text { frequency }\end{array}$ & $\begin{array}{l}\text { Number of tubes and lanes, geometry } \\
\text { (lane width, slope, emergency lane } \\
\text { etc.), lay-bys }\end{array}$ & $\begin{array}{l}\text { Transportation of dangerous goods (time } \\
\text { windows, platoon, escorting), speed } \\
\text { limits, overtaking, safe driving distances }\end{array}$ \\
$\begin{array}{lll}\text { Decreasing of } \\
\text { accident } \\
\text { consequences }\end{array}$ & $\begin{array}{l}\text { drainage system, emergency stations, } \\
\text { water supply, emergency lighting, } \\
\text { ventilation, CCTV, communication } \\
\text { (radiofrequency, loudspeakers). }\end{array}$ & $\begin{array}{l}\text { control center, closure time \& method, } \\
\text { training, periodic exercises, information } \\
\text { campaigns, safe congestion distances (5 }\end{array}$ \\
\hline
\end{tabular}

analysis in different time periods throughout the tunnel design life. Firstly, all possible safety measures are identified and recorded. These safety measures are additional to the minimum safety requirements for tunnels set by Directive 2004/54/EC [1]. All possible combinations of the additional safety measures are examined through quantified risk analysis and the residual risk is estimated for every combination [2] [3] [4]. A certain time period is selected, and the associated costs of safety measures and residual risk are estimated for the specific time period. A cost benefit analysis [5] [6] [7] is conducted with the goal of minimizing the total cost that equals the sum of the cost of each combination of additional safety measures and the cost of the residual risk of the aforementioned combination of safety measures. In case where the minimum total cost estimated through cost benefit analysis is less than the initial cost of the residual risk based on minimum safety requirements, then the specific combination of additional safety measures is adopted and the distribution of cost for financing them is performed between the society (government funding) and tunnel users (tolls).

The proposed methodology provides decision makers a dynamic supporting tool for the funding resources of the additional to the minimum required safety measures. By introducing dynamic parameters of estimating the costs of additional safety measures and residual risk, the need of setting threshold limits and risk acceptance criteria can be questioned. Since, the different parameters that determine the total cost changes over time, the proposed methodology should be applied in regular intervals set by the decision maker.

\section{Methodology-Results}

The proposed methodology involves the consideration of all possible additional measures on the minimum requirements for the increase of safety levels [8]. This can be accomplished either by measures decreasing accident frequency or by measures mitigating the consequences of accidents or combination of them.

The risk reduction measures are initially divided to structural, which concern the structure and the equipment of the tunnel and operational [9], which concern the action plans and operating procedures. Then, the safety measures can 
be divided to those that contribute to decreasing accidents frequency and to those that in case of an accident mitigate their consequences.

The optimization of the planning of a road tunnel can enhance the prevention of road accidents and improve safety levels. Number of tubes and lanes, tunnel geometry and lighting, as well as emergency stations and lay-bys [10] are structural measures which reduce accident frequency. If a long-term forecast of traffic volume indicates that the Annual Average Daily Traffic (AADT) is over 10.000 vehicles per lane, the construction of a second, unidirectional twin tube should be considered, in order the tunnel to be functional when the previous value is exceeded [11]. Generally, the road tunnel should be made in harmony with the category of the road in which is going to be constructed. The geometry of the tunnel is related to the width of traffic lanes, the existence of emergency lane and free traffic space. The previously mentioned geometrical specifications affect extensively the safety of the tunnel. In addition, the lighting of the tunnel must ensure that vehicles should be able to approach, pass through and leave the tunnel during daytime and nighttime, having a speed, safety and comfort levels similar to those in the consecutive open road network" [12]. The main problem of the lighting of the tunnel is the configuration of sufficient lighting in the entrance zone. An excessive level of lighting it is a waste of financial resources in terms of installation and maintenance cost. Finally, the existence of lay-bys is best practice, in case a car breaks down inside the tunnel. In that way, accidents that are caused by immobilized vehicle in a traffic lane, can be prevented.

The operational measures which reduce accident frequency include the way that works are executed inside the tunnel, the policy of the dangerous goods transportation, the forbiddance or not of overtaking inside the tunnel, safety distances and speed limits. During maintenance works in a unidirectional tube of a road tunnel, the lane which is nearest to the work spot must be closed. That way, personnel is more secure than using only the tunnel emergency walkways [13]. Transportation of dangerous good through road tunnels should be considered by conducting a risk analysis study with a sound and official methodology. Also, ADR agreement should be taken into consideration and the tunnel should be categorized accordingly to one or more of ADR categories for the different time periods. Special operational measures for risk reduction can be taken, based on the results of the risk analysis study. These measures may concern a part or the whole number of vehicles carrying dangerous goods. In addition, the number of car collisions can be reduced by the forbiddance of overtaking and lane switch inside the tunnel. Signs on the road way (white arrows, lanes) or in tunnel walls (LED) assist drivers to maintain the proper distances, while a speed reduction by $10 \mathrm{~km} / \mathrm{h}$ can decrease the accident rate by $10 \%$.

The structural measures which are related to the mitigation of accident consequences are distances between the emergency exits, accessibility of emergency services, drainage system, fire resistance of structures, lighting (normal, safety and evacuation lighting), ventilation, emergency stations, water supply system, 
road signs, monitoring system, equipment to close the tunnel, communication systems and fire resistance of the equipment. Specifically, emergency exits must be placed in a way that assist the users of the road tunnel to reach a safe place in the event of an accident in at most 300 seconds, through the emergency exits [14]. All emergency exits must be easily reached and used by people with disability without external help. If this is not possible, then a sufficient evacuation plan must be developed and implemented. Emergency exits must be painted with green color and the lighting must be sufficient. Finally, emergency exits must remain safe and smokeless for at least 30 minutes from the ignition of the fire [15]. The immediate response of emergency services contributes to the mitigation of accident consequences. Drainage system is proposed to include proper slot gutters, while grates that can cause road accidents should be avoided. Furthermore, in the drainage system flame arrestors should be provided to avoid the spread of fire. Fire resistance of structure must be carefully designed following the appropriate time-temperature curve (ISO 834, RWS, ZTV-ING, $\mathrm{HC}_{\text {inc }}$ ) to avoid spalling [16] [17]. Power supply of the safety lighting must be supported by UPS. Evacuation lighting, such as evacuation marker lights, at a height of no more than $1.5 \mathrm{~m}$ shall be provided to guide tunnel users to evacuate the tunnel on foot, in the event of emergency. The design of ventilation system shall take into account the control of heat and smoke in the event of a fire. Different types of ventilation systems are suggested depending on the tunnel characteristics (length, traffic volume etc.). Special attention should be given in emergency plans for the control fire incident, depending on the location of the fire and its heat release rate. In case of an accident, the ventilation system must immediately get in operation in unidirectional tunnels, if there is no traffic congestion. Since most vehicle fires start as small fires which can be easily extinguished with a portable fire extinguisher, extinguishers should be provided in road tunnels. Portable fire extinguishers should be located in conspicuously marked boxes or recesses at uniformly spaced intervals. The removal of a fire extinguisher from its holder should result in an alarm transmission to a central monitored location. Fire extinguishers should have a minimum content of $6 \mathrm{~kg}$ (when the traffic includes mainly passenger cars) and a maximum of $9 \mathrm{~kg}$ (when heavy goods vehicles are numerous). They should be rated for liquids as well as electrical equipment fires. Emergency telephone should be installed in sidewall niches, SOS stations and at the entrances to cross passages to permit motorists or other personnel passing through the tunnel to alert operators in the Control Center or other predetermined locations, such as Police Stations. Operability of hydrant system ensures proper functionality of the systems attached to it and back up the efforts of fire brigade. Incident detection devices, such as loop detection systems, Closed Circuit Television (CCTV), linear heat detection systems, CO and NOx sensors, are used to provide early detection of traffic incidents or abnormal conditions. Experience with loop detection systems in tunnels indicates that they provide accurate incident alarms during peak traffic conditions. New technology 
is available for use with new and existing tunnel cameras and CCTV to provide Automatic Incident Detection (AID). CO and NOx detectors as well as opacity detectors may be installed along the roadway to provide continuous monitoring of the tunnel air quality. These detectors are also required in road tunnels without mechanical ventilation system when heavy goods vehicles are numerous. Concerning tunnel closing equipment, exclusive use of traffic lights causes problems. One reason is that the red light of the traffic light is not expected in highways and as a result road user do not realize the red traffic light before entering the tunnel. It is suggested that proper traffic management system is provided at $250 \mathrm{~m}, 400 \mathrm{~m}$ and $1.000 \mathrm{~m}$ before tunnel entrance to alert road users of the critical circumstances inside the tunnel and deter drivers from entering the tunnel. The traffic management systems can be constituted by traffic signs with two yellow-lights, which in case of an incident is flashing. Also, variable message signs are recommended. The most efficient communication systems in road tunnels are two-way radio communication, radio re-broadcasting for emergency services, emergency radio messages for tunnel users and mobile phones. Finally, some of the equipment of road tunnels are crucial for the users to escape in case of an emergency, such as emergency exit doors, supply cables and jet fans. The uninterrupted function of this equipment must be ensured in case of fire. Fire resistance of this equipment is recommended to be sustain a fire of $100 \mathrm{MW}$ for a time of period of 90 minutes.

The operational measures which are related to the mitigation of accident consequences include the means for tunnel operation, emergency plans, accidents management policy, control center procedures, tunnel closure and information campaigns. The tunnel manager should be prepared for emergencies by proper training. Personnel must gain the proper skills by participating in emergency exercises and retain a high level of readiness and availability. The knowledge of potential fire scenarios by the control center operators allows for better estimation of the maximum available time for tunnel users to evacuate the tunnel safely. It is often observed that tunnel operators in the Control Center have difficulties in handling fire scenarios. Therefore, an automatic system should be available, and the operator should ensure its proper operation. Self-evacuating and rescue actions by the tunnel users have been proven to be the most effective measures in case of emergencies. Therefore, tunnel users should be trained accordingly for emergency circumstances, by informing them through leaflets and web sites [18] [19].

According to the proposed methodology, a risk analysis is conducting during the first stage for the estimation of the residual risk for each one of the aforementioned additional to the minimum requirements safety measures as well as for every combination of them. The subjective cost parameters include the installation and maintenance cost, while the objective parameters include benefits from reduced fatalities and injuries, environmental consequences and traffic delays. The objectives parameters depend on the range of subjective parameters. The 
cost benefit analysis compares the total cost with the total benefits for every possible set of measures and concludes to the optimum set of safety measures. Therefore, at the second stage of the proposed methodology, a cost benefit analysis is conducted, and the optimum set of design and operating requirements are specified.

The results of the present work include the mathematical modeling of the proposed methodology. In the first stage a risk analysis is conducted to estimate residual risk (including the expected value EV) for every possible set of design and operating parameters. In the second stage the cost benefit analysis is conducted, and the optimum set of design and operating requirements is specified. The methodology for conducting a tunnel risk analysis is given by each member state and includes also considerations for the transportation of dangerous goods [2] [20] [21].

The process of cost benefit analysis includes the estimation of net present value of the total investment in safety measures and the benefits from the reduced residual risk. According to the cost benefit analysis methodology, the expected life cycle cost $C_{t}$ for the safety of an activity is equal to the sum of the total cost of safety measures $C_{s m}$ and the total cost of residual risk $C_{r r^{*}}$

$$
C_{t}=C_{s m}+C_{r r}
$$

Figure 1 presented the calculation of the expected life cycle cost $C_{t}$ as the sum of the total cost of safety measures $C_{s m}$ and the total cost of residual risk $C_{r r}$ versus residual risk. The curve is an approximation of all relevant data acquired through a detailed financial analysis that was based on the structural and operational measures described above, for a specific unidirectional road tunnel.

It is observed that the total cost of safety measures is increased with a decrease in the residual risk, while the cost of residual risk is increased with an increase in the residual risk, as should be expected. The point where the sum of the two aforementioned cost gets its minimum value defines the optimum set of design and operating requirements.

Figure 2 presented the algorithm for the estimation of the minimum expected life cycle cost $C_{t}$ and thereafter the optimum set of design and operating requirements.

$$
C_{t i}=C_{s m i}+C_{r r i}
$$

The total cost of safety measures $C_{s m}$ is equal to the sum of each proposed k safety measure $C_{s m k}$ which depends on the initial cost of installation $C_{s m k i}$, the maintenance cost $C_{s m k m}$, the operation cost $C_{s m k o}$ and the salvage value $C_{s m k s}$ and is calculated by the following equation.

$$
C_{\text {smk }}=C_{s m k i}+C_{s m k m}+C_{s m k o}-C_{s m k s}
$$

The total cost of residual risk $C_{r r}$ is equal to the sum of the human impact cost $C_{h p}$ the cleaning and rehabilitation of accident scene cost $C_{c r}$, the evacuation of the nearby population cost $C_{e v}$ the public property damage $\operatorname{cost} C_{p d}$ the business interruption cost $C_{b i}$ the freight loss and vehicle damage cost $C_{l d}$ and the cost of traffic delay $C_{t d^{*}}$ 


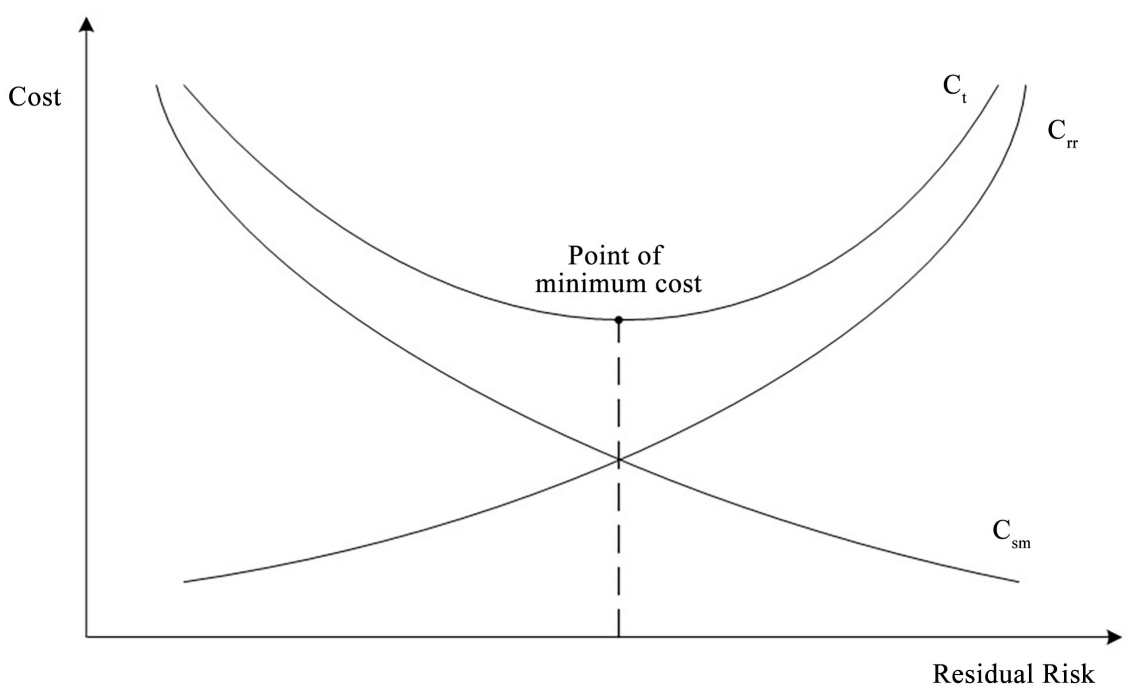

Figure 1. Cost benefit analysis for the definition of the point of minimum cost (correction of the expected life cost and the residual risk).

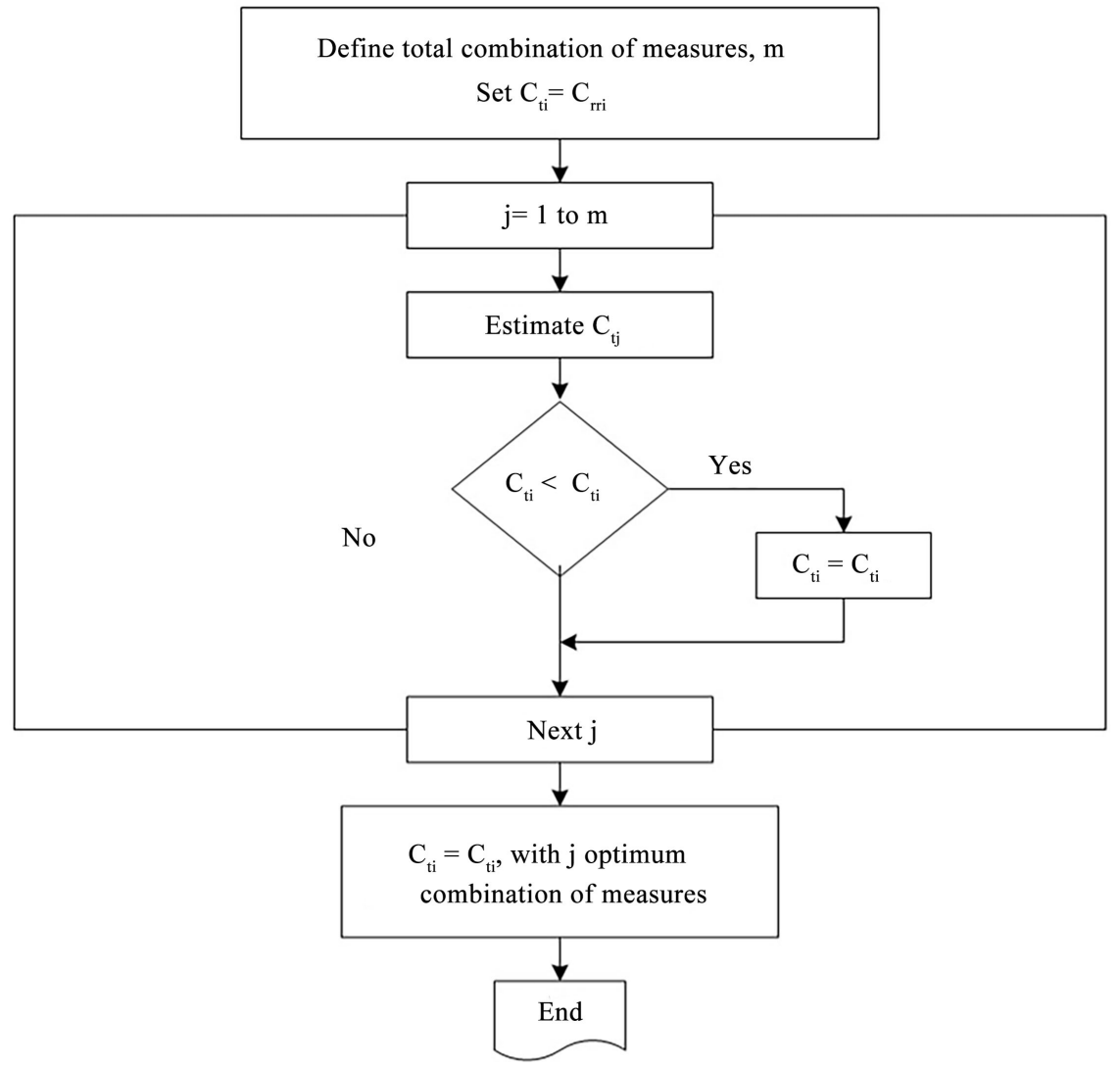

Figure 2. Algorithm for the estimation of minimum cost.

$$
C_{r r}=C_{l d}+C_{t d}+C_{h i}+C_{c r}+C_{e v}+C_{p d}+C_{b i}
$$

The cost of the initial ( $i)$ residual risk $C_{r r i}$ is dictated by the minimum safety requirements set by Directive 2004/54/EC. The final (f) cost of residual risk $C_{r r f}$ is calculated according to the proposed methodology described above, along 
with the cost of additional safety measures $C_{s m f}$

The reduction of residual risk cost $D C_{r r}\left(=D C_{t u}+D C_{s c}\right)$ is divided into two parts. The first part contains all costs $D C_{t u}$ associated with the tunnel users $\left(C_{l d}\right.$ $\left.C_{t d}\right)$, while the second part contains all cost $D C_{s c}$ associated with the society $\left(C_{h p}\right.$ $\left.C_{c r}, C_{e r}, C_{p d}, C_{b i}\right)$.

$$
\begin{gathered}
D C_{t u}=\left(C_{l d f}+C_{t d f}\right)-\left(C_{l d i}+C_{t d i}\right) \\
D C_{s c}=\left(C_{h i f}+C_{c r f}+C_{e v f}+C_{p d f}+C_{b i f}\right)-\left(C_{h i i}+C_{c r i}+C_{e v i}+C_{p d i}+C_{b i i}\right)
\end{gathered}
$$

The beneficiary of cost reduction $D C_{t u}$ is tunnel users, while the beneficiary of the cost reduction $D C_{s c}$ is the society. Therefore, the contribution for tunnel users (tolls) and society (public financing) in the funding of the additional safety measures on the minimum requirements is $C_{t u}$ and $C_{s c}$ respectively and are calculated as follows.

$$
\begin{gathered}
C_{t u}=\frac{D C_{t u}}{D C_{r r}} \cdot C_{s m f} \\
C_{s c}=\frac{D C_{s c}}{D C_{r r}} \cdot C_{s m f}
\end{gathered}
$$

It should be mentioned that all costs in the proposed methodology refers to net present values (NPV) of the specified time period $(\mathrm{t})$ and are calculated by the following equation.

$$
C_{N P V}=\sum_{1}^{t}\left(\frac{C_{1}}{(1+i n f)}+\frac{C_{2}}{(1+i n f)^{2}}+\ldots+\frac{C_{t}}{(1+i n f)^{t}}\right)
$$

where inf is the inflation and $C_{1}, C_{2}, C_{\mathrm{t}}$ are the cash flows in the first, second and $t^{\text {th }}$ year respectively.

\section{Discussion}

The results of the present work include a methodology for determining additional design and operating measures to the minimum required by Directive 2004/54/EC for the safety of road tunnels. The proposed methodology can be proved a useful decision-making tool for contracting tunnel works. Member states can use the proposed methodology to define the additional design and operating measures upon the minimum required for the safety of tunnels in their road network, along with the proper allocation of financing these measures between public financing and tolls. Furthermore, the tunnel manager can use the proposed methodology in order to justify additional operating measures and its related costs for enhancing safety levels during specific time periods and cooperate with administrative authorities for their financing.

Finally, the proposed methodology does not include any specific threshold for risk acceptance criteria. This is a dynamic procedure since additional safety measures are justified mainly through a cost benefit analysis. Therefore, different member states where the monetary value of the costs included in the cost benefit 
analysis vary between them can use the same methodology resulting in different outcomes of optimum design and operating measures, without having to adopt different risk acceptance criteria. Furthermore, since the relation between monetary values among different costs is changing over time, the proposed methodology is an excellent tool for implementing additional safety measures compared to threshold values for risk acceptance criteria.

\section{References}

[1] European Parliament and Council (2004) Directive 2004/54/EC of the European Parliament and of the Council of 29 April 2004 on Minimum Safety Requirements in the Trans-European Road Network. Official Journal of the European Union, L167, 39-91.

[2] Goncalves, N., et al. (2007) Risk Analysis for Road Tunnels. World Road Association, Paris.

[3] OECD (2001) Safety in Tunnels. Transport of Dangerous Goods through Road Tunnels. Organization for Economic Co-operation and Development, Paris.

[4] Vagiokas, N. and Pitsiava-Latinopoulou, M. (2004) Developing a Framework for Assessing Risks Involved in the Transportation of Dangerous Goods. 11 th International Symposium on Loss Prevention and Safety Promotion in the Process Industries, Prague, 31 May-3 June 2004, 1072-1083.

[5] Welte, U., Wierer, A. and Buraczynski, J. (2016) Best Practice for Life Cycle Analysis for Tunnel Equipment. World Road Association, Paris.

[6] ERSO (2008) Cost Benefit Analysis. European Road Safety Observatory, Brussels.

[7] Elvik, R. (2001) Cost-Benefit Analysis of Road Safety Measures: Applicability and Controversies. Accident Analysis and Prevention, 33, 9-17. https://doi.org/10.1016/S0001-4575(00)00010-5

[8] Walet, F., et al. (2012) Assessing and Improving Safety in Existing Road Tunnels. World Road Association, Paris.

[9] Aurand, V., Vagiokas, N., et al. (2017) Road Tunnel Operations: First Steps towards a Sustainable Approach. World Road Association, Paris.

[10] Van der Auwera, K., et al. (2016) Lay Bys and Protection against Lateral Obstacles-Current Practices in Europe. World Road Association, Paris.

[11] Welte, U., et al. (2004) Cross Section Design for Bi-Directional Road Tunnels. World Road Association, Paris.

[12] FHA (2001) European Road Lighting Technologies. US Department of Transportation, Federal Highway Administration, Washington.

[13] Welte, U., et al. (2001) Cross Section Design for Unidirectional Road Tunnels. World Road Association, Paris.

[14] Hejny, H. (2008) Prevention, Detection and Monitoring: Existing Detection and Monitoring Systems. Upgrading of Existing Tunnels: UPTUN, Germany.

[15] Bendelius, A., et al. (2007) Systems and Equipment for Fire and Smoke Control in Road Tunnels. World Road Association, Paris.

[16] Sakkas, K.M., Vagiokas, N.D., et al. (2017) In Situ Fire Test to Assess Tunnel Lining Fire Resistance. Proceedings of the World Tunnel Congress 2017-Surface Challenges-Underground Solutions, Bergen, 9-15 June 2017, 2840-2947.

[17] Lacroix, D. and Haack, A. (2004) PIARC Design Criteria for Resistance to Fire for 
Road Tunnel Structures. Route Roads, 324, 64-71.

[18] Haack, A. (2006) Fire in Tunnels: Design Fire Scenarios. Thematic Network Fire in Tunnels, WTCB, Brussels.

[19] Brekelmans, J. (2008) Promotion, Dissemination, Education/Training and Socioeconomic Impact. Upgrading of Existing Tunnels: UPTUN, The Netherlands.

[20] Hellenic Republic (2001) Guidelines for Risk Analysis of Dangerous Goods Transportation through Road Tunnels According to Presidential Decree 230/2007. Ministry of Infrastructure, Transportation and Utilities, Athens.

[21] Vagiokas, N., Bletsas, A. and Nelisse, R.M.L. (2013) Methodological Approaches for Tunnels Classification According to ADR Agreement. Proceedings of the World Tunnel Congress 2013-Underground-The Way to the Future, Geneva, 31 May-7 June 2013, 314-320. https://doi.org/10.1201/b14769-45 